BULLETIN Bulletin hispanique

HISPANIQUE Université Michel de Montaigne Bordeaux

119-2 | 2017

La Égloga renacentista en el Reino de Nápoles

\title{
«Veder tronca la speme e "l desir morto»
}

I due pellegrini de Tansillo en la urdimbre estilístico-temática de la

Égloga I de Garcilaso

\section{Flavia Gherardi}

\section{Q OpenEdition}

1 Journals

\section{Edición electrónica}

URL: http://journals.openedition.org/bulletinhispanique/5144

DOI: $10.4000 /$ bulletinhispanique.5144

ISSN: 1775-3821

\section{Editor}

Presses universitaires de Bordeaux

\section{Edición impresa}

Fecha de publicación: 1 diciembre 2017

Paginación: 621-638

ISBN: 979-10-300-0218-8

ISSN: 0007-4640

\section{Referencia electrónica}

Flavia Gherardi, ««Veder tronca la speme e "l desir morto»», Bulletin hispanique [En línea], 119-2 | 2017, Publicado el 28 diciembre 2020, consultado el 14 enero 2021. URL: http://journals.openedition.org/ bulletinhispanique/5144 ; DOI: https://doi.org/10.4000/bulletinhispanique.5144 


\title{
"Veder tronca la speme e "l desir morto». $I$ due pellegrini de Tansillo en la urdimbre estilístico-temática de la Égloga I de Garcilaso
}

\author{
Flavia GHerardi \\ Università degli Studi di Napoli Federico II
}

Parmi les antécédents qui ont incité Garcilaso de la Vega à écrire ses Églogues, I due Pellegrini (circa 1527) de Luigi Tansillo se distingue autant pour avoir suggéré au poète tolédan l'argument de l'Églogue I que certains passages textuels concrets qui en marquent la contexture stylistique et thématique. Cet article se propose d'examiner la relation entre les deux œuvres, afin d'évaluer la nature et les caractéristiques de l'influence exercée par le poème du Napolitain sur celui de Garcilaso.

Mots-clés: Garcilaso de la Vega, Luigi Tansillo, églogue, relations hispano-italiennes, littérature pastorale.

Entre los antecedentes que estimularon en Garcilaso de la Vega su proyecto de redacción de las Églogas, I due Pellegrini (1527 ca.) de Luigi Tansillo destaca por haberle proporcionado al toledano tanto el esquema argumental de la Égloga I como una serie de lugares textuales concretos que marcan la urdimbre estilística y temática de la misma. El presente trabajo pretende ahondar en la relación entre las dos obras, a fin de valorar de forma analítica la consistencia y los rasgos de la influencia ejercida por el poema del napolitano.

Palabras clave: Garcilaso de la Vega, Luigi Tansillo, égloga, relaciones hispanoitalianas, literatura pastoril.

Among the antecedents that encouraged Garcilaso de la Vega to compose his 'églogas', 'I due Pellegrini' (1527 ca.) by Luigi Tansillo stands out for having provided to the Toledo poet both the general plot of Eclogue I and a series of textual passages that mark the stylistic and thematic warp of the poem. The present work aims to go deeper into the relations between the two works, in order to evaluate analytically the consistency and the features of the influence exercised by the poem of the Neapolitan.

Keywords: Garcilaso de la Vega, Luigi Tansillo, eclogue, italo-hispanic relationship, pastoral literature. 
$\mathrm{E}$

1 frente de los estudios garcilasianos está conociendo una etapa de especial vitalismo. Lo demuestra el hecho de que las contribuciones más recientes, ciñéndose a enfoques metodológicos renovados, están paulatinamente desembocando en un proceso de revisionismo crítico $^{1}$. En efecto, tras más de medio siglo de indisputada hegemonía del afortunado patrón hermenéutico fijado por Rafael Lapesa con su lectura en «trayectoria» de la poesía del toledano ${ }^{2}$, marcada por la lograda conflatio entre la fijación del dato autobiográfico (viajes, estancias y encuentros, útiles tanto para llevar a cabo el difícil cometido de la datación de los poemas como para justificar su lectura en clave) y la atención a la fisonomía de los poemas, anclada en el propósito de desentrańar el rico entramado de fuentes y modelos intra y extratextuales, se asiste a la propuesta -lo testimonian muchos de los trabajos reunidos en este monográfico-de desviar la atención crítica hacia otros predios metodológicos, como, por ejemplo, el del «campo literario», inspirado en la sociología de Bourdieu -sin que quede expresado ni adoptado de forma ortodoxa-, por medio del cual quede acotada, aclarada y precisada la biografía «intelectual», antes que literaria, del poeta; un enfoque que se ceba en la intersección de saberes -históricos, sociológicos, artísticos- y que hasta el día de hoy no ha sido suficientemente aprovechado en el terreno del garcilasismo ${ }^{3}$.

En ocasión de la apertura del Seminario Internacional «La égloga del Reino de Nápoles en tiempos de Pedro de Toledo», que se celebró en Gerona los pasados 20-21 de octubre de 2016 como actividad relacionada con el proyecto PRONAPOLI, y cuya presentación la coordinadora ha tenido la amabilidad de dejarnos leer, Eugenia Fosalba afirmó sin ambages que

el proyecto se plantea, así, un nuevo acercamiento a la obra de Garcilaso, proponiéndose una inmersión total en el contexto histórico, literario y cultural italiano, para sumergirnos muy especialmente en Nápoles: no nos interesa Garcilaso solo como sujeto pasivo de una serie de influencias, sino, mejor, como un poeta italiano más, inmerso en ese ambiente e interactuando con los demás poetas del momento codo a codo, descubriendo en lengua castellana los caminos que se están empezando a abrir otros poetas italianos amigos suyos que persiguen parejos propósitos a los suyos. Para

1. El presente trabajo se inscribe en el ámbito del Proyecto de Investigación FFI201565093-P «Garcilaso de la Vega en Italia. Estancia en Nápoles» (2016-2019), financiado por el Ministerio de Economía y Competitividad y coordinado por Eugenia Fosalba (Universitat de Girona).

2. En estos términos describía Lapesa el objeto de su clásico estudio: «No parece, sin embargo, inútil el intento de reconstruir los pasos que marcaron el decisivo tránsito del poeta desde el arte de cancionero hasta el mundo quintaesenciado de las églogas, con su paladeo sensorial de todas las bellezas». La referencia, huelga recordarlo, es a Rafael Lapesa, La trayectoria poética de Garcilaso, Madrid, Revista de Occidente, 1948; recogido, con adiciones bibliográficas, en id., Garcilaso: Estudios completos, Madrid, Istmo, 1985. Cito de la p. 11 de esta última edición.

3. Junto con el mencionado, están resultando productivos tanto el enfoque analítico inter artes, destinado a valorar los cruces entre la poesía de Garcilaso y los códigos de la pintura, la escultura, la emblemática, etc., como el inspirado en la Think theory, derivada de la Material Culture, tal y como testimonian los trabajos de Mary Barnard o, en un terreno más amplio, Enrique García Santo Tomás. 
redescubrir este mundo en que vivió Garcilaso de cerca, nos proponemos hacer aflorar ámbitos del saber, textos, relaciones, influencias, tertulias y academias literarias de la Nápoles aragonesa e imperial que todavía se hallen sepultados en el olvido.

Huelga decir que, a medida que van apareciendo los resultados de esos acometimientos investigativos, peligran y, en algún caso, se desmoronan, nada más someterlos a prueba, unos cuantos postulados críticos consolidados por cierta tradición, empezando por la interdependencia entre el esquema de las identificaciones de las personas aludidas en las transfiguraciones poemáticas garcilasianas -en este caso, se trata de un ejercicio en el que los estudiosos nunca han dejado de volcarse, con gusto y con continuidad-y la problemática datación de los poemas, en muchos casos derivada de las primeras. No en otro criterio resultan inspirados, por ejemplo, planteamientos como el que queda expresado en un artículo reciente de la propia Fosalba, aparecido en Ínsula, en el que, relativamente a un famoso soneto de Garcilaso, la estudiosa mantiene:

Se trata de un epitafio puesto en boca del difunto, que expone la paradoja de no haber muerto luchando en el campo de batalla sino por culpa de la enfermedad, la peste negra. Su maestría y corte clásico ha impulsado a la crítica a colocarlo en la época de madurez del poeta, cuando, residiendo en Nápoles, Lapesa lo imagina visitando la tumba de su hermano. ¿Pero, en verdad, qué certeza tenemos de que Garcilaso no estuvo en Nápoles antes de 1532? De hecho, ya Croce, en un opúsculo casi olvidado, daba por seguro que la vida de Garcilaso transcurrió casi íntegramente en Italia desde 1529, lo que daba pie a unas cuantas idas y venidas con respecto a Espańa, pero también a Nápoles y otras zonas de Italia. ${ }^{4}$

De estar así las cosas, y en espera de contrapruebas fehacientes, puede merecer la pena sacar del thesaurus de lecturas intertextuales cuajado en torno a las églogas del toledano un caso, el de la égloga dramática I due pellegrini, compuesta por un joven Luigi Tansillo alrededor de $1527^{5}$, y someter a nueva

4. Eugenia Fosalba, «El desembarco de Garcilaso en Italia», Ínsula, no 825, sept. 2015, pp. 6-8. Cito de la p. 7. Entre los frutos más granados de esta propuesta hay que considerar no solo los trabajos más recientes de la estudiosa («Implicaciones teóricas del alegorismo autobiográfico en la égloga III de Garcilaso», Studia Aurea, vol. 3, 2009, pp. 39-104; «El exordio de la Epístola a Boscán: contexto napolitano», Studia Aurea, vol. 5, 2011, pp. 23-47; «Sobre la relación de Garcilaso con Antonio Tilesio y el círculo de los hermanos Seripando", Cuadernos de filología italiana, no 19, 2012, pp. 131-44; «Más sobre Garcilaso en Nápoles. Epigramas funerales a la muerte de Ariosto", en Encarnación Sánchez García (ed.), Rinascimento meridionale. Napoli e il Viceré Pedro de Toledo (1532-1553), Napoli, Tulio Pironti, 2016, pp. 387-408; «Tracce di una precoce composizione (ca. 1525-1533) del De Poeta di Minturno. A proposito della sua possibile influenza su Garcilaso de la Vega», Critica letteraria, no 173, 2016, pp. 627-650; «Ecos de la preceptiva minturniana en las églogas de Garcilaso de la Vega», aquí contenido), sino también los de otros miembros del proyecto; a saber, más concretamente, los de Gáldrick de la Torre Ávalos, acerca de la corte poética de Ischia, y los de Adalid Nievas Rojas, acerca de la figura del «divino» Aldana, o también los de Tobia R. Toscano, en el frente italianista.

5. La obra de exordio de Luigi Tansillo ha sido transmitida por la princeps impresa de 1631, es decir, posterior en más de un siglo a su primera composición. Durante mucho tiempo se había creído que su redacción se remontaba a 1538 -por ende, con posterioridad a las églogas de Garcilaso-, debido a que el autor recuperó y volvió a manejar el texto en ocasión de una 
consideración su relación con aquellas, más concretamente con la égloga I, de la que el poema napolitano es reconocido antecedente.

El propósito goza de trascendencia propia y se presenta prometedor aun prescindiendo del problema representado por la fecha de composición atribuido a la égloga primera, pues estimamos que desvincular el poema del doble condicionamiento representado por: 1) el convencimiento de que las personae de Salicio-Nemoroso derivan del desdoblamiento de un único yo, el autorial; y 2) que, por consiguiente, los motivos que vertebran sendos lamentos - pérdida por, progresivamente, engańo y muerte de la amada (ambos inherentes a su experiencia amorosa con Isabel Freyre)-, obliga a fijar la redacción de la égloga I a 1534, lo que deja franqueada una parcela nada desdeńable del espacio exegético.

\section{«ACCIÒ CHE D'AMBIDUE QUAL SIA MAGGIOR SI MOSTRI, PARAGONIAMO INSIEME I}

\section{NOSTRI DOLORI»}

La consideración de la dependencia de las églogas de Garcilaso de I due pellegrini durante largo tiempo ha quedado mimetizada en una cadena de transmisión que cuenta con los famosos artículos de Eugenio Mele de 1923 y 1930 en tanto eslabones fundamentales ${ }^{6}$, puesto que es por medio de estos trabajos que las señalaciones ofrecidas ya por Flamini en su edición -si bien

representación teatral que el hijo del virrey Pedro de Toledo, don García, organizó en Messina en 1538 en honor de doña Antonia de Cardona: "La più antica testimonianza di una esecuzione in pubblico dei Due pellegrini è consegnata a un passo delle Sicanicae historiae di Francesco Maurolico nel contesto di un'ampia descrizione dei festeggiamenti offerti in Messina da don García de Toledo, figlio del Viceré, in onore di Antonia de Cardona, figlia del conte di Collesano (o Golisano), alla cui mano aspirava. La sera del 26 dicembre 1538 fece allestire la sala del banchetto sotto un ampio padiglione costruito nel porto di Messina, il cui pavimento fu ottenuto assemblando assi di legno appoggiati sulle fiancate di due triremi alla fonda [...] Prima dell'edizione Flamini, una breve nota di Gasparay aveva chiarito che nel testo vulgato dei Due pellegrini, pur coincidente nelle linee essenziali con la trama sintetizzata da Maurolico, "non si trova nessuna lode per Don Garzia e Donna Antonia, ma invece di loro vengono celebrate due persone affatto differenti", di qui stabilendo che essendo il conte di Nola, Enrico Orsini, finito nella lista dei baroni ribelli per aver inalberato bandiera francese durante l'invasione di Lautrec, la composizione e la rappresentazione dell'opera non potevano essere posteriori al 1528. Pertanto l'egloga drammatica andava considerata l'opera di esordio di un poeta diciottenne, segnata dal desiderio evidente di celebrare non solo i conti di Nola, ma anche la storia e l'amenità del sito della città [...] Tra le due ipotesi possibili: una ripresa pura e semplice del testo originario nella rappresentazione messinese o una ripresa con riadattamento della parte encomiastica alle esigenze del diverso contesto, si può senżaltro convenire con FLAMINI ( $p . X X X I V)$ nel preferire la seconda, tanto più che in un testo assai parco (per non dire privo) di connotazioni ambientali si trattava di intervenire sui pochi versi (1066-84) devoluti all'elogio di Nola e dei suoi signori». Me valgo de la nota al texto que Tobia R. Toscano, quien tiene en preparación la edición de L'Egloga e i poemetti de Tansillo, según la propuesta de Flamini, muy generosamente nos ha facilitado.

6. Eugenio Mele, «Las poesías latinas de Garcilaso de la Vega y su permanencia en Italia», Bulletin Hispanique, vol. 25, 1923, pp. 361-370 e id., "In margine alle poesie di Garcilaso", Bulletin Hispanique, vol. 32, 1930, pp. 218-225. 
antigua, a día de hoy todavía la única disponible- ${ }^{7}$ traspasan literalmente al terreno de la filología española; de ahí recoge la información Lapesa dejándola en la disponibilidad de quienes, posteriormente, se interesarán en la cuestión ${ }^{8}$. Dejando de lado la presencia del dato en la brillante edición de Morros, o también su supervivencia, en tanto idée reçue, en los demás partos de la crítica garcilasiana y no ${ }^{9}$, el único intento de acotación de la cuestión en términos apenas más analíticos se encuentra, aunque de una forma todavía somera, en el estudio de González Miguel, deudor a su vez de las pocas páginas que Erasmo Pèrcopo dedicó a la obra ${ }^{10}$, ambos vinculados, en todo caso, con el frente italianista más que con el hispanista.

7. L'egloga e i poemetti di Luigi Tansillo secondo la genuina lezione dei codici e delle prime stampe, con introduzione e note di Francesco Flamini, Napoli, per i tipi di V. Vecchi, 1893. Para nuestra égloga, véanse esp. las páginas XX-XXXIV.

8. Lapesa, op. cit., p. 125, en donde se lee que «la égloga I recuerda la obra de Tansillo en algún pasaje». En puridad, además de la información proporcionada por los comentaristas antiguos, ya en Keniston los hispanistas podían leer que "this contrast between the woes of the betrayed and the bereaved lovers is found in the Due pellegrini of Luigi Tansillo, which was probably produced as early as 1528 and which Garcilaso must have known", pero sin ninguna indicación de los lugares concretos de la imitación (Garcilaso de la Vega: A Critical Study of His Life and Works, New York, Hispanic Society of America, 1922, p. 241).

9. Valgan como simple botón de muestra las referencias contenidas en Joan Cammarata, Mythological Themes in the Works of Garcilaso de la Vega, Madrid, José Porrúa Turanzas, 1983, en donde se llega a mantener incluso que "Garcilaso imitates and paraphrases I due Pellegrini (1528), Tansillo's Eclogue in dialogue form», p. 21; más prudentemente, José Manuel Trabado Cabado, Poética y pragmática del discurso lírico. El Cancionero pastoril de La Galatea, Madrid, CSIC, 2000, p. 124, remite a un pasaje contenido en la tesis doctoral de Ramón Mateo Mateo sobre La poesía pastoril española del siglo XVI (UNED, 1990) en el que «respecto a la temática de la Égloga I de Garcilaso escribe este mismo autor: "El contenido argumental contaba con larga tradición y se prolongaría en el género pastoril, con variantes y ampliaciones diversas, por todo el siglo XVI" (Ibid., p. 165). Tampoco se ha de olvidar que una de las vías evolutivas de la bucólica de Sannazaro la constituye I due pellegrini de Luigi Tansillo»; en el estudio de Joan Ramón Resina, Los usos del clásico, Barcelona, Anthropos, 1991, p. 125, se lee que «Menéndez Pelayo -Orígenes de la novela, I, Madrid, 1905, p. 328- señaló el precedente de la anónima Questión de amor (1513), y posteriormente se ha indicado otro en I due pellegrini, de Tansillo. E. Mele, "Las poesías latinas de Garcilaso de la Vega", Bulletin Hispanique, XXV (1923), p. 362». Finalmente, en Aldo Ruffinatto y Iole Scamuzzi, Le tre corone in Spagna. Con appendici cervantine in Italia, Torino, Celid, 2008, cap. «Petrarca in Spagna», p. 85, se lee que "oltre che in alcuni sonetti, il dialogo di Garcilaso con Tansillo, in particolare con I due pellegrini, si manifesta chiaramente nella prima Egloga».

10. Luigi Tansillo, Il canzoniere edito ed inedito secondo una copia dell'autografo ed altri manoscritti e stampe, con introducción y notas de Erasmo Pèrcopo, ed. Tobia R. Toscano, Napoli, Consorzio Editoriale Fridericiana, Liguori, 1996, t. I, pp. lxxxiii-lxxxv, y de Jesús-Graciliano González Miguel, Presencia napolitana en el Siglo de Oro español. Luigi Tansillo (1510-1568), Salamanca, Ediciones de la Universidad de Salamanca, 1979. Véase también, del mismo autor, el interesante «De la égloga al drama pastoril. I due Pellegrini de Luigi Tansillo», en J. Espinosa Carbonell (ed.), El teatro italiano. Actas del VII Congreso Nacional de Italianistas, València, Universitat de València, Departament de Filologia francesa i italiana, 1998, pp. 295-307. 
Por lo que atañe a la cuantía de la "deuda» garcilasiana ${ }^{11}$, estos mismos hitos bibliográficos rastrean sus huellas a lo largo de tres vertientes distintas: argumental, textual y estructural, con una curiosa concentración de dichas correspondencias en la égloga primera ${ }^{12}$, frente a las escasez de proyecciones tansillianas en la segunda. El legado más macroscópico estribaría en la adopción de parte del toledano de un esquema argumental parejo al de $I$ due pellegrini, para la síntesis del cual podemos cómodamente remitir al bien decir de González Miguel:

Garcilaso imitó a Tansillo en su primera Égloga: el tema y la situación de los protagonistas son semejantes: Salicio y Nemoroso, lo mismo que Alcinio y Filauto (recuérdese que el nombre de Alcino recurre también en la Égloga III de Garcilaso) ${ }^{13}$ lloran uno el abandono, otro la muerte de la amada. La Égloga de Tansillo es más

11. Cuajada, según lo referido, en la bastante certera hipótesis de que el texto recogido en la prínceps de 1631, que manejamos por mediación de Flamini (quien se coloca en la estela de las ediciones del XVIII y XIX de Piacentini, Ferrario y Masi), correspondiese a la "versión nolana» de la obra y no a la supuesta versión posterior de 1538.

12. Resulta curioso, en efecto, que el recuerdo de Tansillo se haya vuelto más vivo precisamente en la redacción más distanciada, temporalmente, de la lectura de I due pellegrini por parte de Garcilaso. Estando ya rematada a la altura de 1527-28, Garcilaso pudo leer la égloga nada más llegar a Nápoles y conocer al venosino en 1531-2 o, por qué no, incluso antes, en ocasión de sus viajes anteriores a Italia, si por alguna razón pudo entrar en contacto con los manuscritos de Tansillo. La hipótesis podría no ser del todo descabellada si se considera que el éxito de Il Vendemmiatore, que Tansillo compuso antes de 1532 y que de inmediato empezó a circular, pudo arrastrar consigo también a la égloga pastoril que marca su debut literario, a pesar de la opinión contraria de Toscano, quien, en la citada nota al texto de la edición que tiene en preparación, mantiene que «i pochi elementi disponibili sembrano indicare una limitatissima diffusione del testo, sul quale l'autore torna dopo la prima composizione del 1528 per riadattarlo alla rappresentazione messinese del 1538, introducendo le necessarie varianti allo stato non documentabili, prima di estrarne nella fase più matura della sua attività $i$ madrigali 132 e 247 cui si faceva cenno in precedenza. Il tardivo riaffiorare del testo nella princeps del 1631 avviene, attraverso un percorso difficile da ricostruire, nel contesto dell'accademia napoletana degli Erranti, grazie all'iniziativa del Capriccioso Errante, maschera accademica che nasconde l'identità di un editore che somministra alle stampe la versione "nolana" dell'egloga. Né la distanza che separa la composizione dalla pubblicazione deve essere sottovalutata ai fini del giudizio che si voglia dare sui traguardi linguistici raggiunti dal giovane Tansillo». Aun admitiendo la elevada improbabilidad de un contacto temprano con el poema de Tansillo, queda el interrogante de por qué Garcilaso debería haber actuado de una forma regresiva, volviendo precisamente en la composición más tardía a soluciones estéticas menos novedosas (estimuladas por el antecedente napolitano, aunque contaminado y sobrepasado por medio de otros referentes genéricos), que son las que la mantienen anclada en el ejemplo tansilliano.

13. Es más, ańadimos nosotros, fonéticamente es anagrama parcial de Salicio. Alcinio es espańol, procedente del «aureo Tago». Quedan por aclarar las razones por las que Tansillo decidió que el interlocutor de Filauto fuera un español, para el que no se han avanzado hipótesis de identificación, dejando el dato únicamente justificado por medio de la conocida y desbordante hispanofilia del joven Tansillo. Acerca de la técnica anagramática por medio de la cual posiblemente el toledano se autorepresente y deje su firma en la obra, véase el reciente trabajo de Roland Béhar, «The Poetry of Garcilaso: Bucolic Tradition and the Invention of a Visual Signature», Bulletin of Spanish Studies, 2017 (http://dx.doi.org/10.1080/14753820.2017.129 8320). 
dramática, pero son tan largos los monólogos de los protagonistas y se relacionan tan poco entre sí, que más parecen dos lamentos paralelos que un verdadero diálogo. Garcilaso acorta aún más la pobreza dramática y el diálogo desaparece por completo. ${ }^{14}$

Junto con el eje temático, tanto Mele como González Miguel apuntan la imitación directa de parte del toledano en correspondencia con tres pasajes textuales, cada uno relacionado con los motivos metafóricos, respectivamente, del «falso pecho» de Galatea, en el que se oculta el engaño destinado a Salicio; el de la «amada yedra» que, arrancada, se arrima y se queda asida a otro muro; y, finalmente, el tópico en virtud del cual la «voz divina» de la amada se revela tan prodigiosa que puede amansar los vientos airados. En la última vertiente, la estructural -hay que especificar, sin embargo, que en este caso se trata de un contenido ofrecido en entredicho, pues se desprende de forma indirecta, casi ex contrario - la influencia del antecedente napolitano se haría ostensiva en la organización en díptico del parlamento entre los dos protagonistas. Con su disposición, en efecto, $I$ due pellegrini diluye el mecanismo clásico del contrapunto o del canto amebeo, adhiriéndose más a un esquema yuxtapositivo de segmentos complementarios que a una estrecha trabazón entre ellos, por lo menos en lo que atañe a los apartados más significativos del texto, los ocupados por los lamentos amorosos, marcando de esta manera un doble distanciamiento tanto para con el patrón clásico de la égloga bucólica -rasgo que precisamente Garcilaso extremará hasta el punto que «difumina el juego dialógico»- ${ }^{15}$ como para con el otro género del que $I$ due pellegrini resulta deudor, a saber, el debate de procedencia medieval conformado en conexión con la materia bucólica por la famosa Questión de amor (1513), a cuyas espaldas se vislumbran, esperadamente, las trece quaestiones amorosas del IV libro del Filocolo de Boccaccio, ambas obras de ambientación napolitana ${ }^{16}$.

14. González Miguel, op. cit., p. 54

15. «En mayor medida que la bucólica $V$, la égloga I difumina el juego dialógico entre las intervenciones consecutivas en los largos parlamentos, de doce estancias, carentes de la fluida alternancia de tramos más acordes con el patrón clásico, tales como los elogios de Tirreno y Alcino a sus respectivas amadas en la égloga III (vv. 305-308)». Así lo aclara, perfectamente, Soledad Pérez-Abadín Barro, en su «Diálogo, responsio, imitación: claves estructurales de la égloga I de Garcilaso", Lectura y Signo, no 6, 2011, pp. 31-62.

16. La deuda con la Question de amor de dos enamorados, al uno era muerta su amiga, el otro sirve sin esperança de galardon (Valencia, Diego de Gumiel, 1513), en la que se ofrece una representación de la sociedad napolitana, empeñada en la asimilación de la presencia española, a la altura de la primera década del siglo XVI, hasta la batalla de Rávena (1512), se limita a los aspectos temáticos (aunque la desviación del motivo del desdén hacia la traición de la amada es cosecha del propio Tansillo), ya que Flamiano y Vasquirán emprenden un debate que gira en torno a quién sufre más, si el que es desdeńado por la amada (Flamiano) o aquel que, habiendo gozado de ella al principio, ha perdido para siempre su felicidad, pues ella ha muerto y nunca podrá volver a verla. Además, la novelita contiene la «égloga de Torino», una de las primeras piezas dramáticas del teatro espańol, cebada en el modelo bucólico a lo Encina y en la que se viene a ratificar en vía definitiva el casamiento entre el eje argumentativo de la Cuestión con el contexto ficcional de la égloga. Para los detalles relacionados con esta égloga, en la que Torino expresa en un largo parlamento su «dolorido sentir» para luego someterlo al diálogo con 
Pues bien, como puede apreciarse, el conjunto de las correspondencias apuntadas entre las dos églogas constituye un caudal nada desdeñable que, pasado por el tamiz adecuado, puede aportar detalles útiles para integrar en el discurso crítico acerca de la égloga I; sin necesidad, desde luego, de caer con eso en valoraciones excesivamente entusiásticas, pero, sobre todo, sin descuidar que la imitatio garcilasiana siempre estuvo dominada por una tendencia natural, que es propia del genio, al desarrollo de lo que el poeta percibía en sus lecturas como presencia nuclear o solamente embrionaria, no menos que al perfeccionamiento de lo que se le antojaba inconcluso, mejorable o perfectible. $Y$ en general vale también para nuestro objeto de reflexión lo que apuntó Lapesa en relación al aprovechamiento que de Petrarca hizo nuestro poeta en la lamentación de Nemoroso: «En la mayoría de los casos no hay deliberada imitación de un pasaje determinado, sino recuerdo global de varios» ${ }^{17}$. Cabe preguntarse, sin embargo, en qué medida Tansillo, a su vez experto saqueador de Petrarca y Ariosto, pudo coadyuvar aquellos recuerdos.

Sorprende, en efecto, que hasta hoy los datos señalados arriba no hayan rebasado el nivel de la mera indicación bibliográfica, y que nadie, tal vez condicionado por la dominante consigna "Tansillo, imitador del toledano» ${ }^{18}$, se haya esforzado para sopesar más detenidamente la reconocida influencia tansilliana en el complejo y estratificado sistema compositivo de la égloga I. De ahí que nuestro cometido para el presente trabajo sea el de ahondar en cada una de las tres vertientes señaladas, con vistas a apuntalar la variada fenomenología intertextual que marca las dos obras y espigar la modalidad de reúso de aquellos materiales, con su consiguiente renovación estética por parte de Garcilaso.

sus amigos, véase el reciente artículo de Alba Agraz Ortiz, «Entre lírica y teatro: tradiciones y confluencias genéricas en la "Égloga de Torino"", Dicenda. Cuadernos de Filología Hispánica, vol. 34, 2016, pp. 7-32).

17. Lapesa, op. cit., p. 133.

18. En efecto, al ser más joven de diez años, Tansillo pudo gozar, en el curso de su aprendizaje poético, de la sombra benéfica del que «según Bembo, fue el espańol más distinguido, festejado y querido entre cuantos hasta entonces habían vivido en el reino» (González Miguel, op. cit., p. 51). Fue inevitable que el venosino mojara copiosamente su pluma en la tinta vertida por el admirado amigo, hasta el punto de que, según el "pendularismo" imitativo típico de los cerrados círculos literarios de la época, el propio Tansillo «ricambiò l'onore ricevuto [con la imitación garcilasiana de la égloga I], imitando, a sua volta, la suddetta egloga nelle canzoni pescatorie, dove don Garzia di Toledo assume lo stesso nome di "Albano" [...]" (Pèrcopo, op. cit., p. lxxxix). Acerca de los avatares de estos vaivenes, véase también el estudio de Roland Béhar recogido en este mismo número. 


\section{«Il TANSILlo CHE FA MOVER LE PIANTE COI CARMI, E I FIUMI STAR FERMO» ${ }^{19}$}

En primer lugar, habría que calibrar de qué manera I duepellegrini proporciona sus sugerencias con relación a fenómenos textuales muy contenidos en su extensión, tales como sintagmas, iuncturae, locuciones y soluciones lingüísticas de variado cariz.

En este sentido, en el espléndido sintagma garcilasiano "con canto acordado" (v. 49), que introduce la performance canora de Salicio, puede reconocerse una clara reminiscencia sannazariana: «Mentre il mio canto e 'l mormorar dell'onde I s'accorderanno» (egl. II, vv. 7-8) ${ }^{20}$.

Sin embargo, la fórmula escogida por Garcilaso resulta textualmente más cercana, en parte por su exitosa organización fónica (merced a la distribución tripartita del fonema /c/), a la solución adoptada por Tansillo: «convien canto c'accordi» (v. 456); si bien, desde el punto de vista conceptual, la correspondencia se da, efectivamente, más con el contexto de la Arcadia (un canto acorde con el sonido producido por las aguas corrientes) que con el de la favola pastoral en la que, por el contrario, los dos peregrinos (nunca, por cierto, calificados de pastores) se plantean un canto que no sea acorde con sus propios sentidos, esto es, con su íntimo anhelo de muerte ${ }^{21}$. Ciertamente, puede que la familiaridad lingüística entre la pareja de versos sea accidental, pero se nos antoja que, aun teniendo a Sannazaro como "guía» conceptual, la elección de Tansillo debió parecerle a Garcilaso estéticamente preferible.

De la misma manera, no sabemos si nos hallamos frente a un préstamo directo a la hora de comprobar si la interrogación que Garcilaso hace pronunciar a Salicio: «Tu quebrantada fe, ¿dó la pusiste?» (v. 130), reproduce el tansilliano «mirar la rotta fede e l'altrui frode» (v. 299) ${ }^{22}$, que, si bien se trata de una expresión corriente en la lengua y la poesía del XVI (en Ariosto, por ejemplo, recurre a menudo, pero asociada a otros contextos), es en Tansillo donde aparece vinculada a una paralela situación de engaño sentimental.

Asimismo, nos preguntamos si, en relación con el famoso estribillo que jalona el lamento de Salicio, «Salid, sin duelo, lágrimas, corriendo», que ya Herrera puso oportunamente en relación con las Lamentaciones de amor de Garci Sánchez de Badajoz (vv. 7-10), para luego ser emparentado por la crítica

19. La fórmula-retrato está sacada del último canto del Amadigi de Bernardo Tasso.

20. Se cita a partir de la siguiente edición: Iacopo Sannazaro, Arcadia, ed. Carlo Vecce, Roma, Carocci, 2013, p. 81.

21. Precisamente esta conformación ex contrario del canto al contexto natural-siempre que tal conformación se logre, pues el texto lo calla-, no posibilita que en la égloga del venosino haya «un eco de la armonía existente entre la emoción humana y el fenómeno natural; armonía expresada en el "canto acordado" del verso precedente y que constituye la nota básica del poema [garcilasiano] entero" (Lapesa, op. cit., p. 127): estamos frente al giro de tuerca que, en su conjunto, el toledano hace realizar a la égloga dramática en dirección de su lirización.

22. El sintagma aparece también en el v. 823: «...la rotta fe, gl'inganni». 
también con pasajes parejos del Canzoniere o de la Arcadia $^{23}$, no habría que considerar también el verso de Tansillo "Prega le luci mie, di pianger vaghe, / che diano il passo a la dolente voce» (vv. 69-70) como un eslabón más de aquella cadena de transmisión, puesto que con el estribillo garcilasiano comparte tanto el elemento temático del llanto («lágrimas-piangen») como el componente gramatical del predicado con función imperativa asociado a la acción de movimiento ("Salid-che diano il passo»), además de la condensación (en Tansillo limitada al segundo hemistiquio), con efecto eufónico, de la dental /d/ y la correspondencia lexemática «duelo-dolente».

Por último, no resultará baladí señalar la estrecha cercanía entre el v. 222, en el que Salicio hace acto de generosa cesión del lugar «al que todo mi bien quitar me puede», y el v. 803, en el que Alcino considera que su amada "e s'ogni ben m'ha tolto, I mè pur questa una gloria almen rimasta, / ch'io posso dire "io fui": or tanto basta». El valor de la correspondencia, en este caso, no estriba tanto en la semejanza del sintagma («todo mi bien» / «ogni ben»), que entronca con la lexicalización ya secular del «sommo bene» petrarquista, sino en la presencia del mismo en un parejo contexto discursivo, presidido precisamente por el propósito del abandono como reacción al «quitar» del otro.

Por lo que, en cambio, atañe a los loci objeto de imitación, que ya han sido señalados por la crítica desde hace tiempo, no deja de ser curioso que Garcilaso recupere los tres pasajes (dos pronunciados por Salicio, el tercero por Nemoroso) respetando, más o menos, la misma colocación o distanciamiento espacial que guardan en el original. Los primeros dos, que, cercanos entre ellos, en Tansillo constituyen momentos articulatorios de una exposición indirecta -el dialogante está reconstruyendo el antecedente en beneficio de su interlocutor-, en la égloga I pasan a ser incorporados en el diálogo imaginario que Salicio mantiene con Galatea ausente. El principio dialógico, que en el modelo vertebra la macrostructura, pero que resulta despotenciado a nivel microestructural por la exposición prolongada del personaje, con consecuente pérdida de tensión textual, en Garcilaso se vuelve precisamente el recurso que garantiza la intensidad emotiva que marca aquellos versos concentrados -otro acierto del toledano- en pocas estrofas:

Quante volte mi disse: Ah mar di gioia,
quanto veggio m’è noia e quanto ascolto
ove non è il tuo volto! ${ }^{24}$ Io lo credea:
miser non m'accorgea, chill falso petto
copriva altro concetto, altro desio,
dando a nuovo amador quel che fu mio
(vv. 130-135); ${ }^{25}$

23. Para más detallada información, baste con remitir a las esmeradas notas complementarias que acompañan al texto en la edición realizada por Bienvenido Morros (Barcelona, Crítica, 1995, pp. 459-460), de la que citamos a lo largo de este estudio.

24. Conceptualmente, este pasaje coincide con lo expresado por Salicio a propósito de la cercanía pasada de Galatea: «¿D’una te desdeñas ser señora / donde siempre moraste, no pudiendo / de ella salir un hora?» (vv. 67-69).

25. Muy pertinentemente, Flamini anota: «Limitatore, come s’è mostrato nell'Introduzione, 
;Ay, cuánto m’engañaba!

iAy, cuán diferente era

y cuán d'otra manera

lo que en tu falso pecho s'escondía!

(vv. 105-108).

Es indudable, en efecto, que la interjección en la que el toledano enmarca el préstamo tansilliano extrema el efecto de patetismo que hace inolvidables estos versos, al tiempo que, por medio de la extensión del paralelismo sintáctico a lo largo de los tres heptasílabos, combinada con el valor semántico de la otredad (diferente-otra) -esto es, obtener el contraste entre la repetición y la variaciónvehicula con una fuerza mucho mayor que en el original la idea de enajenación del yo frente a la felicidad pasada.

Por lo que atañe a la siguiente correspondencia intertextual:

La vite da me solo amata e colta

vidi in altr'olmo avvolta, $e$ ' $n$ gioia e in pace;

l'edera mia seguace dal mio? scinta

$e$ in altro muro avvinta $i$ vaghi rami,

cherano miei legami; e i torti passi

vider quest'occhi, lassi, e non fu sonno!

(vv. 166-171); ${ }^{26}$

No hay corazón que baste,

aunque fuese de piedra,

viendo mi amada yedra

de mí arrancada, en otro muro asida,

y mi parra en otro olmo entretejida,

que no s'esté con llanto deshaciendo

hasta acabar la vida

(vv. 133-139),

no deja de hacerse notar la curiosa inversión en el orden de aparición de los elementos vegetales en la elaboración garcilasiana (prolongación de la imagen anterior de los brazos que envuelven el cuello), que, por otro lado, respeta casi al pie de la letra las conexiones "vidi-viendo", «olmo avvolta-olmo entretejida», "edera mia-mi amada yedra", "dal mio scinta-de mi arrancada", tal vez para posibilitar el eficaz paralelismo: «de mí arrancada, en otro muro asida, / y mi parra en otro olmo entretejida", mucho menos perceptible en el contexto tansilliano. Además, importa notar que la función escóptica, señalada por

dovett'essere Garcilaso" (op. cit., p. 8).

26. Flamini reincide en el dato: "Probabilmente qui lo Spagnuolo imitava il nostro, e a sua volta questi ripeteva un motivo popolare». Mele, al señalar la misma relación, produce una errata: atribuye a Tansillo la imitación queriendo escribir Garcilaso. Es un evidente lapsus calami que, sin embargo, se ha arrastrado en las proyecciones posteriores de la cuestión, hasta el punto que el propio Lapesa se deja condicionar por la mala lectura, declarándose en contra de Flamini cuando en realidad comparte su idea: «Los pasajes garcilasianos inspirados en Tansillo son los versos 105-108 y 135-139. No comparto la opinión de Flamini, para quien el imitador en el segundo caso, es Tansillo; véase Mele, “"Bull. Hisp.” XXXII, pág. 220» (op. cit., p. 125). 
medio del verbo que vertebra el pasaje entero, "vidi-viendo", en el contexto de la égloga italiana, resulta coherente con el hecho de que, desde los versos anteriores, se está refiriendo a sus propios ojos, mientras que en la española pasa a ser referido a un metonímico corazón protagonista de una formulación que apunta a mote sentencioso: «No hay corazón que...».

Finalmente, la adynaton de la voz de la amada, capaz de amansar los vientos, representa el caso de coincidencia intertextual de más difícil valoración, puesto que, a pesar de ser acertada su señalación por parte de Mele como ańadidura a la reminiscencia petrarquesca (Canzoniere, cccxxv, vv. 86-87) ya apuntada por el Brocense, en virtud de su mayor cercanía lingüística y sintáctica («concon», «e-y», "accenti-acentos», "aria $i$ venti-airados vientos»), el contexto de procedencia resulta ser totalmente distinto. Filauto inserta el elogio hiperbólico en el marco de la extensa laus de la belleza de su amada, organizada según el patrón tópico del fraccionamiento de los elementos corporales (pelo, ojos, mejillas, boca), mientras que Nemoroso aprovecha el elemento de mirabilia dentro de un contexto memorial (el estatuto de recuerdo es el único elemento común a los dos empleos) que desemboca en la tremebunda visión (recuerda e imagina, a la vez, a la amada puesta en el «duro trance» del parto mortal), cuya conexión con la materia mitológica aumenta su estatuto sobrenatural y, por tanto, perturbador:

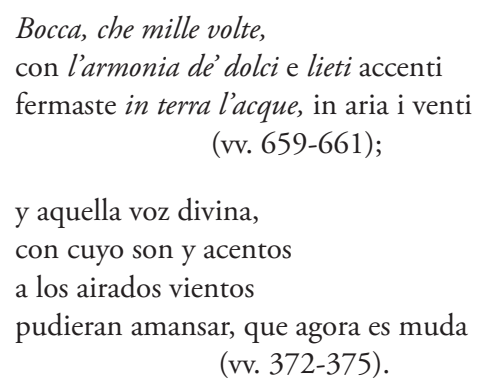

Como se habrá notado, la casi totalidad de las correspondencias señaladas se concentran en la porción de lamento puesta a cargo de Salicio, es decir, del amante apremiado por la necesidad de expresar su resentimiento, no ya por el desdén de su amada sino por su traición y consiguiente defraudación de expectativas. Ahora bien, si por un momento cediéramos a la tentación de transportar el dato al plano de las hipótesis que se van sucediendo acerca de la redacción de la égloga I (si fue compuesta de un tirón o por fases, si fue concebida y compuesta solo después de 1533, a raíz de la muerte de Isabel Freyre, o si tuvo una gestación larga, en la que el poeta estuvo ocupado entre 1531 y 1534), casi parecería quedar afianzada la propuesta -defendida en su momento por Entwistle ${ }^{27}$ de que la égloga fue compuesta por bloques y no

27. W. J. Entwistle, «La Date de l'Égloga primera de Garcilaso de la Vega», Bulletin Hispanique, vol. 32, 1930, pp. 254-256. Es de sobra conocido que, contra esta hipótesis, Lapesa (y con él otros estudiosos del calibre de Rivers o Navarro Tomás) defiende: «A nuestro modo de ver, no pueden admitirse dudas sobre la unidad de concepción patente en la égloga primera [...] La uniformidad 
de forma unitaria, y que la redacción del canto de Salicio es muy adosada, cronológicamente, a la celebración de la boda de Isabel Freyre con Antonio de Fonseca, a su vez curiosamente cercana, en el tiempo, a la redacción de $I$ due pellegrini. Sin embargo, a falta de pruebas, lo único que pueden avalar los datos recogidos -en consonancia con la tensión que cohesiona el doble lamento- es que, a la hora de conformar a la expresión poética el malestar -suyo o no- por las desavenencias con la "falsa perjura", Garcilaso tuvo a mano -y no solo vagamente presente- la égloga del joven amigo.

Dicha cercanía queda aquilatada por medio de otra estrategia reveladora de los mecanismos de elaboración garcilasiana: la observación del punto de calado de los injertos tansillianos dentro de la urdimbre temática y estilística de la égloga del toledano. Descontando todo lo que Garcilaso quiso desechar de su antecedente, queda fuera de duda que, por ejemplo, una imagen como la de la yedra asida a otro muro ocupa un lugar fundamental del texto, desarrollando una función esencial para la economía de conjunto de la égloga I: constituye el clímax de la parábola diseńada por el lamento de Salicio. De la misma manera, la imagen del "falso pecho» es la que regula el pasaje desde la dimensión del pasado hacia la del presente y, por ende, articula por entero la dialéctica entre presencia y ausencia de la amada ${ }^{28}$.

Los últimos considerandos nos desplazan directamente al segundo de los espacios de verificación anunciados arriba, el temático.

En este terreno, si bien hallamos confirmada la mayor incidencia de $I$ due pellegrini en la canción de Salicio, nos encontramos con alguna -posibleproyección de la obra en el segmento protagonizado por Nemoroso e incluso fuera de la propia égloga I.

En el contexto de la égloga garcilasiana, uno de los tópicos más productivos resulta ser el tema del castigo, combinado con la pronunciación de anatema, en dańo y venganza de la amada traicionera. Los comentaristas antiguos y modernos hacen acertado hincapié en la raigambre clásica del motivo, aunque subrayan que el hipotexto directo de Garcilaso es, con toda probabilidad, Ariosto con varios pasajes del Orlando furioso ${ }^{29}$. Ahora bien, el tema del castigo $^{30}$, pero sobre todo el de la «ingorda gelosia», de la envidia azuzada por la conciencia de que el otro, sin merecerlo, goza de su antiguo bien, y del rabiar por «veder in man d'altrui quel guiderdone, I di cui le mie fatiche mi

de la maestría estilística garantiza la continuidad del proceso creador» (op. cit., p. 126).

28. Acerca de la función desarrollada por el lugar en su relación con el yo amante, en la doble dimensión de pasado y de presente, es prescriptivo remitir al espléndido estudio de Antonio Gargano, "Questo nostro caduco et fragil bene". Forme e significati del 'locus amoenus' nell'Egloga I di Garcilaso", en G. Calabrò (ed.), Signoria di parole. Studi offerti a Mario Di Pinto, Napoli, Liguori, 1998, pp. 283-298.

29. Acerca de la evolución esencial de este tópico, véanse las páginas 460-461 de la mencionada edición de Morros.

30. «Quanto si scemerebbe del mio duolo, / quanto la morte mi saria più grata, / se chi si vive del bel cibo mio / morisse qual moro io!» (L. Tansillo, I due pellegrini, ed. cit., vv. 753-756). 
fean degno» (vv. 375-376), es una materia que domina el ductus expositivo de Alcino, reiterándose frecuentemente en su discurso ${ }^{31}$.

El motivo del pastor que decide suicidarse ocupa un espacio relevante dentro de la pastoral de Tansillo, puesto que al aparecer bastante pronto, nada más poner fin Alcino y Filauto a la «lite corta» acerca de "qual sia maggion» dolor, se convierte en principio unificador tanto de la materia (las personalidades de los protagonistas, a partir de ese momento, ya no están en contraste, sino que «comparten» tanto el recuerdo de sus amadas como el propósito de la doble muerte) como de su disposición, puesto que mantiene vinculado a su realización (convencionalmente frustrada por la intervención salvífica de una "anima» oracular, detalle de raigambre virgiliana) el desarrollo posterior de la obra. A pesar de su consistencia, sin embargo, el tema no dejó huella en la primera de las églogas de Garcilaso; en cambio, sí pudo tener cierta proyección en el episodio de Albanio de la égloga segunda, si bien tanto el hecho de que ahí el tópico sufre una reductio ad unum, coherente con la mayoría de los antecedentes (entre ellos, el Filenio de la égloga II de Gallo) como el de la modalidad escogida (Albanio intenta arrojarse al agua, a la zaga de Carino) inducen a pensar que, en la reelaboración del hipotexto sannazariano, la reminiscencia de la égloga de Tansillo no funcionaría sino como un estímulo más ${ }^{32}$.

Tampoco se demostró muy sensible Garcilaso a las potencialidades de un tema como el de la ceguera del amante, bien si ciego por haber perdido su «lume», o bien si deseoso de serlo por no tener que asistir al espectáculo que el mal presente le depara continuamente a los ojos. Se trata de una metáfora que se reitera muy a menudo dentro de la gramática discursiva de $I$ due pellegrini, pues representa el elemento de mayor continuidad con la obra, la Cecaria (1525), de Epicuro (al siglo, Antonio Marsi), considerada su verdadero texto fuente ${ }^{33}$. Solo en un conocido caso Garcilaso echa mano de la poderosa

31. El tópico de los celos está en el centro de uno de esos problemáticos movimientos pendulares mencionados arriba que marcan el proceso imitativo de Tansillo y Garcilaso, puesto que vuelve a menudo en la producción de ambos poetas ajena al espacio de las églogas. Así, por ejemplo, describe la cuestión Milburn: "It is possible that Tansillo's image derives from a very similar poem on jealousy by Garcilaso de la Vega, in which jealousy is the child of love and envy; however given the close friendship between the two poets, and the early date of Tansillo's sonnet, it is not clear which of the two poems imitates the othern. Véanse de la estudiosa, coautora junto con Tobia R. Toscano y Carmine Boccia de una valiosa edición de las Rime de Tansillo, su tesis doctoral: Luigi Tansillo and Lyric Poetry in Sixteenth-century Naples, Leeds (UK), Maney Publishing, vol. 57, 2003, de la que citamos (p. 160), junto con el artículo, más tarde confluido en la misma tesis, "'D’Invidia e d'Amor figlia sì ria”: Jealousy and the Italian Renaissance Lyric», The Modern Language Review, vol. 97, $\mathrm{n}^{\circ} 3$, julio 2002, pp. 577-591.

32. El tema del suicidio le llega a Tansillo, bien directamente de Sannazaro, bien por medio de la mencionada Question de amor, que a su vez lo recibe de su antecedente directo, la "égloga de Fileno» de Juan del Encina, donde el pastor sí llega a suicidarse, y que el autor redacta al arrimo de una égloga de Filenio Gallo, en conexión con el cual -he ahí el juego circular (y por eso problemático) de las influencias- elabora su propio modelo Sannazaro (según las conocidas comprobaciones de Maria Corti).

33. Del semiplagio de Tansillo habló Italo Palmarini, empeñado en refutar la pretendida 
imagen: en la estrofa IV del canto de Nemoroso (v. 295), cuando, al lamentar los efectos -sobre todo la soledad- de la mano cargada del cielo contra él, se declara "ciego, sin lumbre en cárcel tenebrosa»; un verso cuyo parentesco con Petrarca («e m'ai lasciato qui misero e solo [...] veggendo ai colli oscura notte intorno" y "chiuse 'I mio lume e'l suo carcer terrestro») y con Sannazaro ("quella I che cieco mi lasció senza il suo lume») podría validarse sobre la base de un nuevo cotejo con estos versos del venosino:

Ma io, dolente, cieco, sconsolato, con qual speranza scemerò il martire? S'oscurato è il mio sol, morto il mio bene, chi mi può dar più lume o trar di pene? (vv. 267-270);

Et io, ben che disposto Era a trar l'alma fuor del carcer ceco (vv. 498-499).

Versos que, si llaman nuestra atención, no es tanto por ese «aire de familia» que inevitablemente comparten con las miles de variaciones ataraceadas en toda la lírica moderna, sino sobre todo por la progresión trimembre «doliente, cieco, sconsolato", que, rincarando el «misero e solo» de Petrarca (donde, en todo caso, no aparece el adjetivo "ciego»), nos llevan directamente al bello clímax garcilasiano. Sannazaro, una vez más, banalmente podría ser patrimonio común o paradero último de la mediación tansilliana.

Hay otro eje temático, sin embargo, que sí tiene todo el aspecto de la «sugerencia» proporcionada por el diálogo entre Filauto y Alcino. Nos referimos al motivo de la muerte apresurada, ansiada por el amante, en su variante de solicitud dirigida a la amada; motivo que, huelga recordarlo, en Garcilaso conforma la emocionante secuencia de versos (estrofa 29, vv. 394407) que cierra el canto de Nemoroso y, con él, el poema entero:

Divina Elisa [...]

¿por qué de mí te olvidas y no pides

que se apresure el tiempo en que este velo

rompa del cuerpo y verme libre pueda...

En Tansillo se da en una versión mucho menos eficaz:

E, se priego mortal da lei sintende,

fate che venga il più che può veloce;

che quanto indugia più, tanto più noce

(vv. 791-793);

primacía de I due Pellegrini respecto del género del drama pastoral: «A ciò io aggiungo che non solo sono una servile imitazione, ma assolutamente un saccheggio di concetto generale, di pensieri, d'andamento psichico, di metrica e persino di frasi» ("La Cecaria», en Marc'Antonio Epicuro, I drammi pastorali di Ant. Marsi detto l'Epicuro Napolitano, ed. I. Palmarini, Bologna, Commissione per i testi di Lingua, 1969, t. II, p. 15). En efecto, la obra de Tansillo, que también se aparta en muchos rasgos de la Cecaria, parece ser el fruto de una calibrada conmistión entre el drama de Epicuro, la bucólica clásica y la Question. 
ruego que se reitera poco más adelante, pero esta vez dirigido a Amor:

\section{Concedimi, signor, che sciolta l'alma possa andare a trovarla, ov'ella sia}

(vv. 861-862).

Ahora bien, la cuestión se vuelve interesante si más allá de las analogías de situación paramos mientes en dos aspectos nada secundarios. En primer lugar, hay que subrayar que en I due pellegrini, en poco más de ciento cincuenta versos (del 791 al 951) la imagen del alma desligada del cuerpo y, por fin, libre, se reitera no menos de cinco veces: una recurrencia, rayana en la isotopía, suficiente para grabarse en la memoria del lector más despistado ${ }^{34}$. En segundo lugar, en relación más concreta con "este velo rompa del cuerpo", por la que los comentaristas han señalado el inevitable antecedente petrarquesco (Canzoniere, cccxiii, vv. 12-14 y cccxlix, vv. 9-11), junto con una, más cercana textualmente, fuente ariostea (Orlando furioso, xlii, xiv, 7), precisamente el dato numérico, combinado con la obsesiva ariostofilia del napolitano -como de la casi totalidad de los poetas de su generación- y con el carácter esclerotizado de la imagen, pudieron sugerirle a Garcilaso la preciosa, por impactante, desviación del «soltar» hacia el «romper».

Por lo que atañe a la última vertiente, la estructural, desde la cual ya pudimos atisbar al principio alguna, aunque endeble, conexión, queda por señalar lo siguiente: a la hora de fijar los modelos estructurales que pudieron marcar el diseńo églogico del toledano, casi unánimemente reconocidos en las bucólicas VIII (por lo que atañe al dispositivo del canto alternado) y V (en lo que respecta al modelo responsivo con función de contrapeso al binarismo estructural), los estudios críticos llegan a señalar que, a pesar de esta filiación, la égloga I de Garcilaso muestra dotarse de una factura «teatral» ajena al arquetipo virgiliano $^{35}$, al tiempo que «difumina el juego dialógico entre las intervenciones consecutivas en los largos parlamentos, de doce estancias, carentes de fluida alternancia de tramos más acordes con el patrón clásico» ${ }^{36}$. Ahora bien, tal vez quepa preguntarse si esta doble variación -tenue calidad teatral y dilución del patrón dialógico en los dos largos parlamentos- no podrían estar lejanamente condicionados por la lectura sesgada del poema tansilliano, cuyos rasgos

34. "pria che l'alma infelice scioglia e svele» (v. 819), "Deposto ch'avrà l'alma il mortal velo» (v. 844), "Concedimi, signor, che sciolta l'alma» (v. 861), «l'alma esce lieta, e l corpo mor contento» (v. 883), «dal dí che svelta dal mortal mio velo» (v. 951).

35. Pérez-Abadín Barro, op. cit., p. 34: «Los movimientos de entrada y salida de los personajes, en un escenario situado en el paisaje pastoril, que al final del poema ocultan sombras nocturnas, a modo de telón, acerca el poema a una representación dramática, para sugerir esa dimensión asociada al poema bucólico desde sus orígenes. Esa factura narrativa y teatral que sirve de soporte al lirismo no se advierte en la égloga VIII de Virgilio, consistente en la yuxtaposición de dos cantos sin vínculos perceptibles».

36. Pérez-Abadín Barro, op. cit., p. 36, al que remitimos para la reconstrucción de todos estos aspectos, pero sobre todo por la fina y aguda lectura del pendant aédico. 
estructurales definidores, al fin y al cabo, se corresponden precisamente con su natura de égloga pastoril "cuasi» dramática ${ }^{37}$ y la prolongada exposición de las dos lamentaciones ${ }^{38}$.

«QUASI IN UNA RAPSODIA» ${ }^{39}$

«Es obvio que para un poeta tan genial como Garcilaso la asimilación de un modelo no debe separarse nunca de la propensión a emprender nuevos caminos» ${ }^{40}$; pues es obvio también que, en la fragua del genio toledano, I due pellegrini no podía constituir más que un caldero donde poder terminar de

37. En el mencionado estudio de 1988, Graciliano González da cuenta de cómo I due pellegrini «nos ofrece un testimonio importante y muy valioso para el estudio de la evolución de la égloga en dirección del drama pastoril» (p. 306). También Palmarini, en su introducción a la Cecaria de Epicuro, había hecho hincapié en este status "transicional» de la obrita, puesta en vilo entre la «favola boschereccia» y el «drama pastoril», a cuya adscripción como obra iniciadora contestaba con dureza.

38. Quizás haya que buscar el legado más consistente del experimento tansilliano en relación con la problemática armazón estructural de la égloga II más que con la I. Razonando tan solo en términos de soluciones de conjunto, nos preguntamos: a la altura de los años treinta, ¿cuántos ejemplos de égloga pastoril en vulgar pudo conocer Garcilaso, en los que la materia amorosa, vinculada a la dolorosa experiencia de la pérdida, se acoplara a la égloga panegírica (más allá de los no del todo logrados intentos de Sannazaro de «amalgamar», tanto estilística como temáticamente, las "cosas menores» con las «mayores») yuxtaponiendo en díptico el segmento dramático con el encomiástico (precisamente según esta secuencia) tal y como ocurre en $I$ due pellegrini, donde el discurso celebrativo, dirigido al conde de Nola con su casa, se injerta en el tejido eglógico, por más inri, precisamente por intervención del discurso profético de una presencia sobrenatural? Con todas las salvedades posibles, el cometido queda para el estudioso que se anime a profundizar en la cuestión.

39. La expresión es referida por Francesco Tateo a la modalidad compositiva de Tansillo. La retomamos relacionándola con Garcilaso. Véase del autor, "Aspects de la littérature pastorale dans le sud de l'Italie aux XVI e et XVII siècles", en AA.VV., Le genre pastoral en Europe du XV au $X V I I^{\circ}$ siècle, Saint-Étienne, Centre d'Études de la Renaissance et de l'Âge classique, Publications de l'Université de Saint Étienne, 1980, pp. 35-46; recogido, ampliado y traducido con el titulo de «Giardino principesco e paradiso biblico», en id., Chierici e feudatari del Mezzogiorno, Bari, Laterza, 1984, pp. 115-143, de donde citamos, p. 120.

40. Antonio Gargano, «La égloga en Nápoles entre Sannazaro y Garcilaso», en B. López Bueno (ed.), La égloga. VI Encuentro Internacional sobre Poesía del Siglo de Oro, Sevilla, Grupo PASO, Secretariado de Publicaciones de la Universidad de Sevilla, 2002, pp. 57-76. Cit. en p. 70. Acerca del lugar ocupado por la égloga de Tansillo en el desarrollo del género en área napolitana, el esclarecedor estudio de Gargano especifica que «en el período que ahora nos interesa, pese a ser el momento de la máxima fortuna del género y de la supremacía de Sananzaro, en Nápoles la bucólica desaparece [...] Habrá que esperar la cuarta década del siglo para asistir al renacimiento de la égloga en vulgar. En no más de un lustro, un grupo de poetas, todos -o casi todos-amigos de Garcilaso, promovieron su despertar: al inicio de la década se remontaría, en efecto, I due pellegrini de Tansillo; entre el '31 y el '34, Tasso compuso las siete églogas que una vez publicadas formaron una sección particular de la segunda edición de los Amori; en el '33, Bernardino Rota componía 13 églogas piscatorias, que salieron impresas muchos años más tarde; al '35, por último, se remontan las tres églogas de Antonio Minturno, con las que se introdujo en Nápoles la novedad métrica del género que acabo de mencionar» (p. 69). 
forjar algunas imágenes especialmente atractivas por su plasticidad (el falso pecho como escondite del engaño, el velo del cuerpo transustanciado en una losa a romper, y alguna otra imagen más), o en el que acuñar las pequeñas armas lingüísticas con las que fomentar y exaltar la contienda de sus pastores. También pudo en algún caso funcionar como rehilete para acelerar el salto hacia ciertos predios poéticos -ellos, sí, realmente modélicos para él-, como fueron Virgilio, Petrarca, Sannazaro o Ariosto. Diversamente, Garcilaso, que, en virtud de aquella natural propensión a experimentar lo nuevo, ya estaba listo para emprender el nuevo camino que le llevaría, si no le había llevado ya, a traspasar hábil y muy logradamente la materia bucólica de los perímetros del lirismo, fijados ya por Sannazaro, a los del canto elegíaco, en el que armonizó el dulce lamentar de sus pastores en el prisma de la subjetividad, debió de sentirse muy poco seducido por la fórmula puesta a punto por Tansillo; una fórmula que olía demasiado a juego lúdico o a puro adiestramiento cortesano ${ }^{41}$, pues sofocaba los afectos más íntimos de los peregrinos-pastores bajo el peso de la insinceridad poética y el distanciamiento emotivo. No: en su componer rapsódico, Garcilaso debió de sentir que aquella cuerda no era adecuada para su lira, y que hacer del luto por la pérdida no ya un mero tema vertebrador de la urdimbre estilístico-retórica del canto sino la condición estatutaria del yo del que arrancaba aquel canto, era lo único que posibilitaría que «la égloga primera marca[ra] la más alta cima de la poesía garcilasiana» ${ }^{42}$.

41. Sobre estos aspectos del poema de Tansillo, véase el mencionado estudio de Tateo.

42. La cita está sacada del ya más veces mencionado estudio de Lapesa, p. 140. 